\title{
Welcome to Neuroimmunology and Neuroinflammation: a new open access journal for neuroscience
}

\author{
Gang Zhao ${ }^{1}$, Thomas Müller ${ }^{2}$ \\ ${ }^{1}$ Department of Neurology, Xijing Hospital, Forth Military Medical University, Xi'an 710032, Shaanxi, China. \\ ${ }^{2}$ Department of Neurology, St. Joseph Hospital Berlin-Weissensee, 13088 Berlin, Germany.
}

\section{BACKGROUND}

The nervous and the immune system are two essential components of the human body. The developing research in neuroscience and immunology demonstrated that these two systems complement and interact with each other. ${ }^{[1]}$ Details of function and cooperation at the molecular level of both systems are not revealed to date.

Inflammation involves the innate and adaptive immune system. It is a normal response to infection. However, uncontrolled progress of inflammation results in the onset of autoimmune or autoinflammatory disorders. Characteristics of inflammation appear in many neurological diseases, including meningitis, encephalitis, multiple sclerosis, Alzheimer's disease, Parkinson's disease, and epilepsy. ${ }^{[2,3]}$ Recent researches in this area focused on the role of immune cells and immune mediators in the initiation and progression of specific neurological diseases. ${ }^{[4,5]}$ Further, pharmacological inhibition of inflammation pathways will be able to safely reverse or slow the course of these diseases.

This hot topic brings together review and opinion articles that describe our current understanding of the crosstalk between the nervous and immune systems, of the immunopathogenesis and of emergent immunotherapies for specific neurological conditions. ${ }^{[3]}$

\begin{tabular}{|l|l|}
\hline \multicolumn{2}{|c|}{ Access this article online } \\
\hline Quick Response Code: & Website: \\
\hline & www.nnjournal.net \\
\hline & \\
\hline
\end{tabular}

Currently there are more than 600 journals which focus on "neuro". However at present, only six journals focus on neuroimmunology, four of which have been included by Science Citation Index (SCI). To sum up, there was a necessity to found a journal, which is devoted to this field. Neuroimmunology and Neuroinflammation (Neuroimmunol Neuroinflammation), a new journal, is envisioned and founded to represent the growing needs of medical science. It is aimed at publishing high quality articles to promote the development of neuroimmunology.

\section{BRIEF INTRODUCTION OF THE JOURNAL}

Neuroimmunol Neuroinflammation is a new peerreviewed, open access, online journal. The journal is an official journal of the Chinese Society of Neuroinfection and Cerebrospinal Fluid Cytology, and aims to build an open and international academic exchange platform, to promote the exchange of ideas and experiences, and then to improve the academic levels of neuroscience. Primarily focusing on neuroimmunology and neuroinflammation, it extends to biology, pathology, physiology, pharmacology, endocrinology, psychology, oncology, etc. The various types of manuscripts, including original articles, review articles, case reports, commentaries, editorials, and letters to the editors are published in Neuroimmunol Neuroinflammation.

\section{THE EDITORIAL BOARD}

The editorial board is composed of 145 experts and scholars from more than 20 countries. Their specialties cover different areas of neuroscience, such as neuroimmunology, neuroinflammation, neurobiology, and neuropharmacology. They are responsible for

Corresponding Author: Prof. Gang Zhao, Department of Neurology, Xijing Hospital, Forth Military Medical University, No. 169 Changle West Road, Xi'an 710032, Shaanxi, China. E-mail: zhaogang@fmmu.edu.cn 
assessing the manuscripts to ensure the quality of the manuscripts. They are also in charge of soliciting and recommending the manuscripts, and promoting the development of the journal.

\section{WHY OPEN ACCESS PUBLISHING?}

Neuroimmunol Neuroinflammation allows free access (Open Access) to its contents and permits authors to self-archive final accepted version of the articles on any Open Archives Initiative-compliant institutional/subject-based repository. The journal does not charge for submission, processing or publication of manuscripts and even for color reproduction of photographs.

Open access publishing has several significant benefits over the traditional publication model, including: (i) rapid peer review; (ii) high visibility and accessibility; (iii) vastly reduced time period between acceptance of a manuscript and its publication; (iv) the author retains copyright; (v) web-based flexibility.

\section{THE AIM OF THE JOURNAL}

The plan of the journal is to be indexed by PubMed
Central in 1 year and by SCI within 2 years. The objective is great, but every member of the editorial board will try his best. We think in the near future, it will come true!

\section{REFERENCES}

1. Clarkson BD, Héninger E, Harris MG, Lee J, Sandor M, Fabry Z. Innate-adaptive crosstalk: how dendritic cells shape immune responses in the CNS. Adv Exp Med Biol 2012;946:309-33.

2. Glass CK, Saijo K, Winner B, Marchetto MC, Gage FH. Mechanisms underlying inflammation in neurodegeneration. Cell 2010;140:918-34.

3. Vezzani A, French J, Bartfai T, Baram TZ. The role of inflammation in epilepsy. Nat Rev Neurol 2011;7:31-40.

4. Cohen JA, Barkhof F, Comi G, Hartung HP, Khatri BO, Montalban X, Pelletier J, Capra R, Gallo P, Izquierdo G, Tiel-Wilck K, de Vera A, Jin J, Stites T, Wu S, Aradhye S, Kappos L; TRANSFORMS Study Group. Oral fingolimod or intramuscular interferon for relapsing multiple sclerosis. $N$ Engl J Med 2010;362:402-15.

5. Vezzani A, Granata T. Brain inflammation in epilepsy: experimental and clinical evidence. Epilepsia 2005;46:1724-43.

Cite this article as: Zhao G, Müller T. Welcome to Neuroimmunology and Neuroinflammation: a new open access journal for neuroscience. Neuroimmunol Neuroinflammation 2014;1(1):1-2.

Source of Support: Nil. Conflict of Interest: No.

Received: 30-04-2014; Accepted: 19-05-2014 